\title{
Simental Irkı Bir Buzağıda Çoklu Ürogenital Sistem Anomalisi**
}

\author{
Sadık YAYLA ${ }^{1 *}$, Engin KILIÇ ${ }^{1}$, Hasan ÖZEN² ${ }^{2}$, Vedat BARAN ${ }^{1}$, Uğur AYDIN ${ }^{1}$, Emin KARAKURT ${ }^{2}$ \\ ${ }^{1}$ Kafkas Üniversitesi, Veteriner Fakültesi, Cerrahi Anabilim Dalı, Kars, Türkiye. \\ ${ }^{2}$ Kafkas Üniversitesi, Veteriner Fakültesi, Patoloji Anabilim Dalı, Kars, Türkiye.
}

Geliș Tarihi: 27.10.2016

Kabul Tarihi: 06.01.2017

\begin{abstract}
Özet: Bu olgu sunumunda; bir buzağıda çoklu ürogenital sistem anomalisi olarak bilinen ve atresia ani et vulva, kloaka oluşumu, vaginal ektopi ve koksigeal agenesiyi içeren olgunun tanımlanması ve sağaltım sonuçlarının değerlendirilmesi amaçlandı. Olgumuzu kuyruk yokluğu ve perineal bölgede bir kitle şikâyeti ile kliniğimize getirilen simental ırkı, 2 günlük bir buzağı oluşturdu. Yapılan klinik muayenede; atresia ani, atresia vulva ve perineal bölgede yaklaşık $8 \times 10 \times 25 \mathrm{~cm}$ büyüklüğünde fluktuan bir kitle saptandı. Kitle sedasyon ve lokal infiltrasyon anestezisi eşliğinde cerrahi olarak ekstirpe edildi ve histopatolojik incelemede vagina mukozası ile uyumlu non-keratinize çok katlı yassı epitelyum belirlendi. Postoperatif dönemde hayvanın sorunsuz bir şekilde defakasyon ve ürinasyonunu yaptığı belirlendi. Sonuç olarak; bu olgu sunumu ile benzer vakalar açısından klinik pratiğe ve literatüre katkı sağlanacağı düşünüldü.
\end{abstract}

Anahtar Kelimeler: Atrezia ani, Atrezia vulva, Kloaka oluşumu, Buzağı.

\section{Multi Urogenital System Anomalies in a Simmental Calf}

\begin{abstract}
The purpose of this case presentation was to describe multi organ anomalies, including atresia ani and vulva, cloacal formation, vaginal ectopy, and coccygeal agenesis, in urogenital system of a calf, and to evaluate the results of the treatment. The case material was a 2-day old Simmental calf brought to the clinic with complaints of a mass at the perineal area and the lack of tail. Clinical examination revealed atresia ani, atresia vulva and a fluctuant mass sizing $8 \times 10 \times 25 \mathrm{~cm}$ at the perineal region. Under sedation and local infiltration anesthesia, the mass was surgically extirpated and in histopathological examination it was determined non-keratinized stratified squamous epithelium, which complies with the vaginal mucosa histomorphology. In follow up, the animal was seen to defecate and urinate with no problems. In conclusion, the present case contributes to clinical practice and to the literature in terms of similar cases.

Keywords: Atresia ani, Atresia vulva, Cloacal Formation, Calf.
\end{abstract}

\section{Giriş}

Birçok evcil hayvan türünde farklı sistemlere ait anomalilerinin bir arada veya ayrı ayrı şekillenebileceği; bunlar arasında atresia ani, rektovaginal fistül, kolon agenezi yaygın olarak yer tutarken rektouretral fistül, agenesi ve ektopilerin daha nadir olarak görüldüğü rapor edilmiştir (Aslan ve ark., 2009; Belge ve ark., 2000; Durmuş ve Çınar, 2011; İşler ve ark., 2016; Kılıç ve ark., 2005; Kılıç ve ark, 2006; Şındak ve ark., 2010; Yayla ve ark., 2016). Ayrıca, birçok sistemi içine alan çoklu kongenital anomalilerin tek bir hayvanda görülebileceği de bilinmektedir (Doğan ve Şındak, 2013; Durmuş ve Çınar, 2011; Kılıç ve ark, 2006; Şındak ve ark., 2010). Kongenital anomalilerin nedenlerinin belirlenmesi her zaman mümkün olmamakla beraber çoğu zaman mutasyon, kromozomal defektler, viral veya bakteriyel enfeksiyon, intoksikasyon ve gebelikte yetersiz veya kötü beslenme ile ilişkilendirilmektedir. Özellikle gebeliğin erken dönemlerinde yapılan rektal palpasyon ya da diğer farklı çevresel faktörlerinde etkili olabileceği düşünülmektedir (Durmuş ve Çınar, 2011; Kılıç ve ark., 2005; Kılıç ve ark. 2006; Yayla ve ark., 2016). Özellikle çiftlik hayvanlarında tespit edilen anomali veya malformasyonların sağaltımında temel amaç; hayvanın yaşamını sürdürerek kasaplık bir değere ulaşmasına katkı sağlamak yönünde olmaktır (Kılıç ve ark. 2006, Kılıç ve ark. 2015).

$\mathrm{Bu}$ olgu sunumunda bir buzağıda karşılaşılan atresia ani, atresia vulva, kloaka oluşumu, vaginal ektopi ve koksigeal agenesiyi içeren çoklu ürogenital sistem anomalisinin tanımlanması ve uygulanan sağaltım sonuçlarının bir arada değerlendirilmesi amaçlandı.

\section{Olgu Tanımı}

Olgumuzu kuyruk yokluğu ve perineal bölgede bir kitle şikâyeti ile Kafkas Üniversitesi Veteriner Fakültesi Cerrahi Anabilim Dalı Kliniğine getirilen simental ırkı, 2 günlük bir buzağı oluşturdu (Şekil 1). Buzağının defakasyon veya ürinasyon yapmadığı, ancak kitlenin uç kısmının dışkı ile bulaşık olduğu ve buranın detaylı incelendiğinde toplu iğne başı büyüklüğünde bir fistül ağzının olduğu görüldü. Bu fistül deliğinin doğuştan mı yoksa sonradan mı oluştuğu yönünde gerek anamnez gerekse klinik muayene sonuçlarına göre kesin bir yargıya varılamadı. 
Yapılan klinik muayenede; koksigeal agenesi, atresia ani et vulva ve perineal bölgeden başlayıp inguinal bölgeye kadar uzanan ve bu bölgede geriye doğru dirseklenme gösteren yaklaşık $8 \times 10 \times 25 \mathrm{~cm}$ büyüklüğünde fluktuan bir kitle saptandı (Şekil 2). $\mathrm{Bu}$ kitlenin total olarak ekstirpe edilmesi kararlaştırılan olguda operasyon için sedasyon (0.2 $\mathrm{mg} / \mathrm{kg} /$ intramusküler, xylazine $\mathrm{HCl}$, Rompun ${ }^{\circledR}$, Bayer) ve lokal infiltrasyon $(20 \mathrm{ml}, \% 2$ lidokain $\mathrm{HCl}$, Adokain $^{\circledR}$, Sanovel) anestezisi tercih edildi. Traşdezenfenksiyon ve bölgenin sınırlandırılması gibi rutin operasyon hazırlıklarını takiben kitlenin dip kısmına sirküler bir şekilde yapılan ensizyonla bölgeye ulaşıldı (Şekil 3). Operasyon sırasında kitlenin lumenli bir yapıda olduğu ve vagina olduğundan şüphe duyulan kesenin dorsalde rektum ile kloakal bir yapı şeklinde birleştiği görüldü. Kitle içeriğinin ise sulu kıvamından dolayı mekonyumla karışık idrar olabileceği yorumlandı. Asepsi ve antisepsi kurallarına gereken özen gösterilerek kitle içeriği bir böbrek küvet içerisine boşaltıldıktan sonra kese şeklindeki yapı ekstirpe edildi. Daha sonra dorsalde yer alan kloaka yapısına (Şekil 4) herhangi bir müdahalede bulunulmaksızın bölgede oluşan kitle yatağındaki kas ve deri karşı karşıya getirilerek bölge kapatıldı.

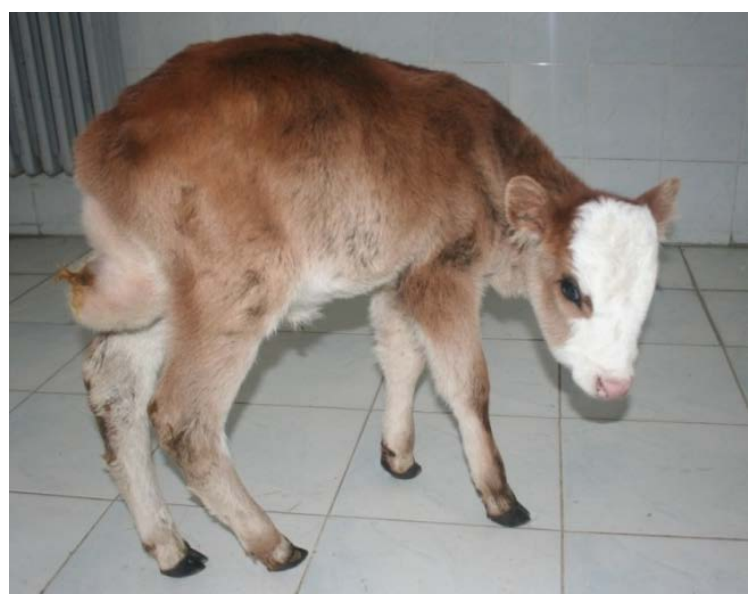

Şekil 1. Olgunun preoperatif görünümü.

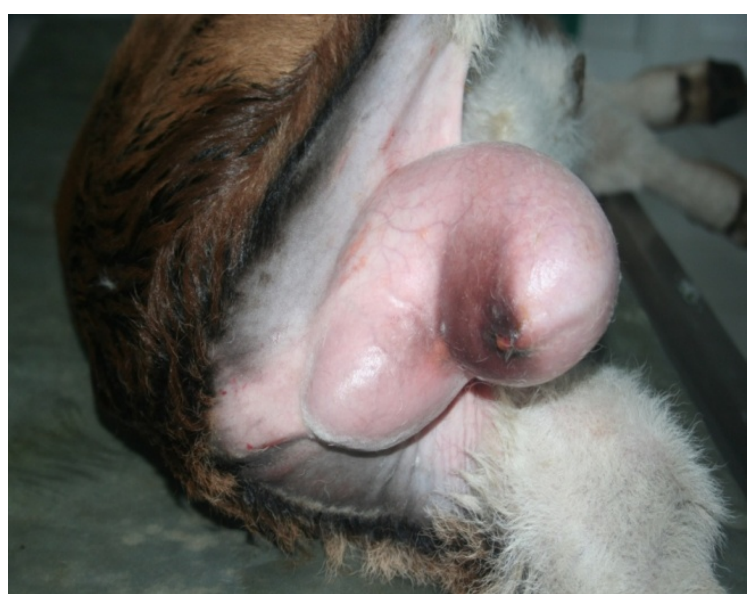

Şekil 2. Kitlenin preoperatif görünümü.

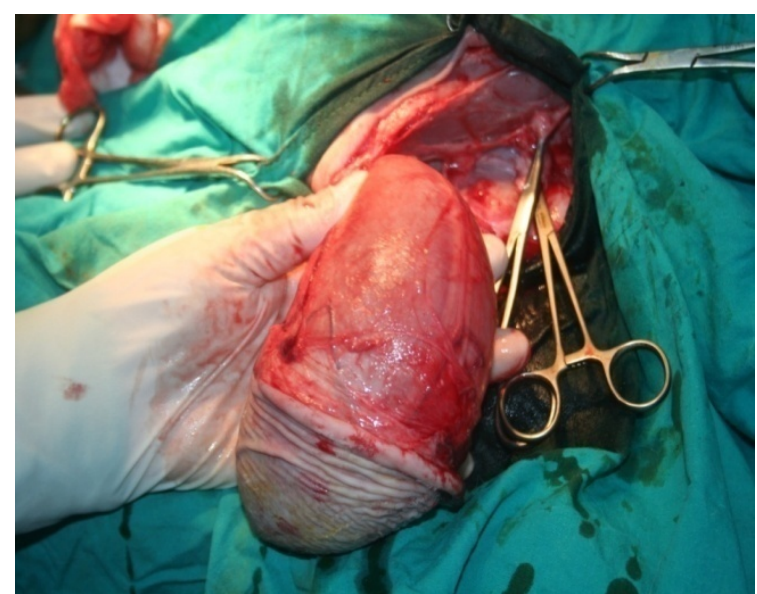

Şekil 3. Kitlenin operasyon sırasında görünümü.

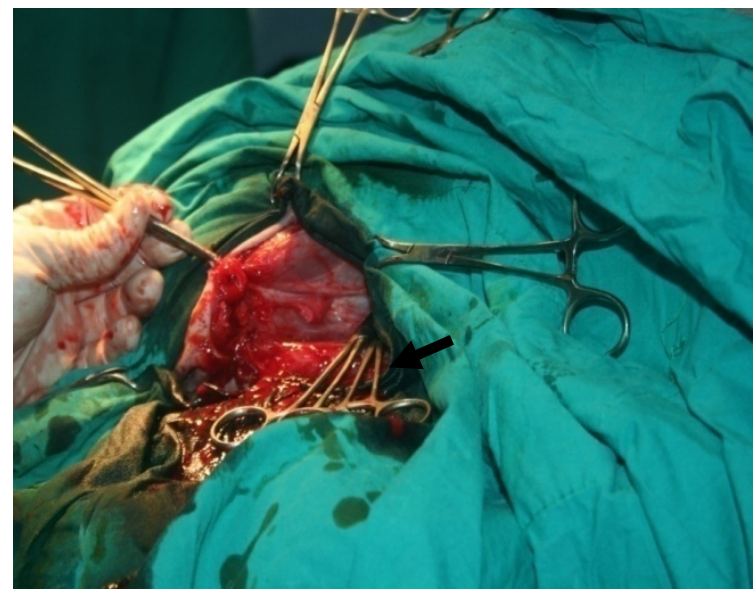

Şekil 4. Kitle uzaklaştırıldıktan sonra kloakal yapı (siyah ok).

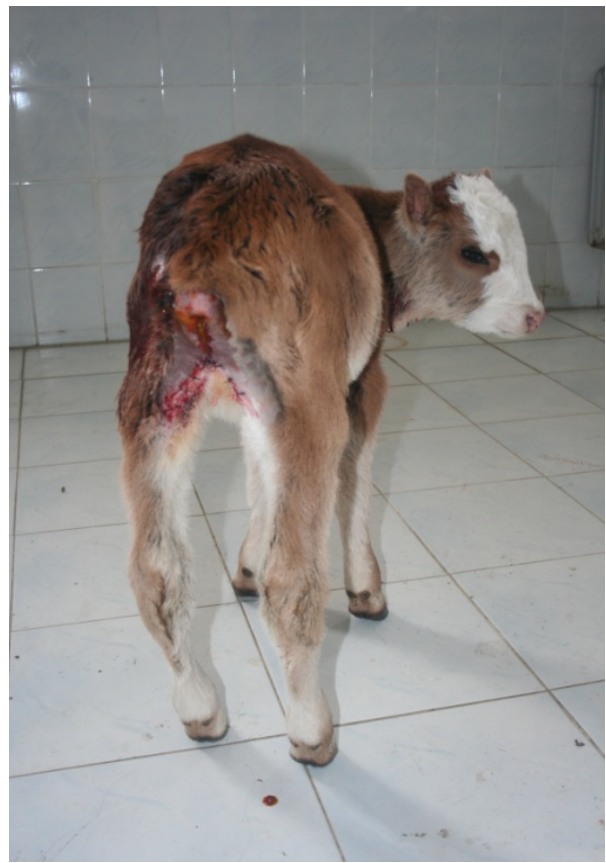

Şekil 5. Olgunun postoperatif görünümü. 


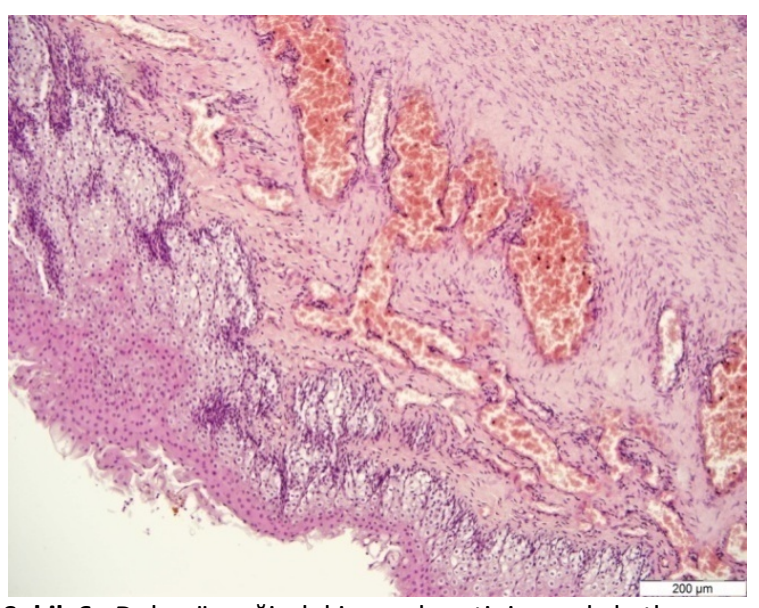

Şekil 6. Doku örneğindeki non-keratinize çok katlı yassı epitelyum ve çok sayıda submukozal damar, hematoksilen eozin.

Postoperatif bir hafta süre ile antibiyoterapi ve yara bakımı yapıldı $(10,000$ IU benzilpenicillin prokain, $10 \mathrm{mg}$ dihidrostreptomycin sulphate, Reptopen S, CEVA-DIF). Postoperatif dönemde hayvanın sorunsuz bir şekilde defakasyon ve ürinasyonunu bu kloakal yapıdan bazen bir arada bazen de ayrı ayrı yaptığı görüldü (Şekil 5). Daha sonra operasyondan sonraki ilk bir ay boyunca yapılan takiplerde buzağının normal gelişiminde aksama olmadığı ve genel durumunun iyi olduğu öğrenildi. Ekstirpe edilen kitleden alınan doku örnekleri \%10'luk tamponlu formaldehitte tespit edildi. Rutin işlemlerin ardından hazırlanan kesitler Hematoksilen eozin ile boyanarak ışık mikroskobunda incelendi. Histopatolojik bulgulara dayanarak kitlenin vagina mukozası ile uyumlu non-keratinize çok katlı yassı epitelden oluştuğu tespit edildi (Şekil $6)$.

\section{Tartışma ve Sonuç}

Diğer bir çok hayvan türünde olduğu gibi buzağılarda da uretral stenosis, dilatasyon, divertikulum, atresia gibi ürogenital anomalilerin atresia ani, atresia ani et rekti ya da rektovaginal fistül ile birlikte görülebileceği farklı bir çok yazarca (Bademkıran ve ark., 2009; Durmuş ve Çınar 2011; İşler ve ark., 2016; Kılıç ve ark., 2005; Kılıç ve ark., 2015; Kılıç ve ark., 2006; Krishna ve ark., 2009; Shakoor ve ark., 2012; Şındak ve ark., 2010; Yayla ve ark., 2016) bildirilmiştir. Olgumuzda ise atresia ani, atresia vulva, kloaka oluşumu, vaginal ektopi ve koksigeal agenesiyi içeren çoklu ürogenital sistem anomalisi olarak tanımlandı. Bu olguda ektopik vaginadan oluşan bir kese içerisinde kloakal kanaldan gelen dışkı ve idrar karışımı birikerek kitlenin zamanla büyüyerek yaklaşık $8 \times 10 \times 25 \mathrm{~cm}$ hacmine ulaştığı düşünülmüştür. Operasyon sırasında vagina benzeri yapının vücudun dışında ampül benzer bir kese şeklini aldığı ve perineal bölge düzeyinde idrarla dışkının karışımına bağlı olarak fluktuan bir kitleye dönüştüğü anlaşılmış, ancak vaginal yapı olarak yorumlanan bu organ normal lokalizasyonuna getirilememiştir. Yapılan histopatolojik incelemelerde bu kitleden alınan kesitlerin vagina mukozası ile uyumlu non-keratinize çok katlı yassı epitelden olduğu tespit edilmiş ve ektopik mega vagina tanısı konmuştur.

Sindirim sistemiyle birlikte çoğunlukla ürogenital sistemin de dahil olduğu çoklu anomali veya malformasyonların patogenezi tam olarak bilinmemekle birlikte genetik ve çevresel faktörleri de içine alan değişik birçok faktörün etkili olduğu düşünülmektedir (Aslan ve ark., 2009; Belge ve ark., 2000; Doğan ve Şındak, 2013; Durmuş ve Çınar, 2011; Kılıç ve ark., 2005; Kılıç ve ark, 2006; Şındak ve ark., 2010; Yayla ve ark., 2016). Nedenin saptanması birçok açıdan önemli olmasına rağmen sunulan bu olguda nedenin belirlenmesine yönelik imkânlar ölçüsünde herhangi bir girişimde bulunulmamıştır. $\mathrm{Bu}$ olguda hayvanın kasaplık bir değer kazanana kadar bile olsa normal yaşamını sürdürmesine yardımcı olunması amaçlandı ve uygulanan operasyonla buzağının ürinasyon ve defekasyon yaparak akranları gibi besi performansına ulaştığı anlaşımıştır.

Sonuç olarak bu olgu sunumu ile simental ırkı iki günlük bir buzağıda karşılaşılan atresia ani, atresia vulva, kloaka oluşumu, vaginal ektopi ve koksigeal agenesiyi de içeren çoklu ürogenital sistem anomalisi tanımlanarak, vakanın raporlanması ile özellikle saha şartlarında çalışan meslektaşlarımıza benzer olguları değerlendirmede ışık tutacağı ve literatüre katkı sunacağı düşünülmüştür.

\section{Kaynaklar}

Aslan L, Karasu A, Gençcelep M, Bakır B, Alkan I, 2009: Ruminantlarda konjenital anorektal anomali olgularının değerlendirilmesi. YYÜ Vet Fak Derg, 20, 1, 31-36.

Belge A, Gönenci R, Biricik HS, Ormancl S, 2000: Buzağılarda doğmasal anomali olguları. YYÜ Vet Fak Derg, 11, 2, 23-26.

Doğan H, Şındak N, 2013: Nizip ve köylerindeki buzağı, kuzu ve oğlaklarda anomalilerin insidansı ve bu olgularda bazı biyokimyasal değerlerin belirlenmesi. Harran Üniv Vet Fak Derg, 2, 2, 61-66.

Durmuş AS, Çınar HN, 2011: A case of rectovaginal fistula, atresia ani and perosomus elumbus in a calf. FÜ Sag Bil Vet Derg, 25, 1, 43-47.

Issler CT, Altuğ ME, Gönenci R, Aytekin I, 2016: Bir koyun işletmesinde görülen anomali vakalarının değerlendirilmesi. Harran Üniv Vet Fak Derg, 5, 1, 74-76. 
Kılıç E, Öztürk S, Aksoy O, Özaydın I, Özba B, Dağ-Erginsoy $S$, 2005: Preputial aplasia, uretral diverticulum and distal uretral atrazia in kids. Kafkas Üniv Vet Fak Derg, 11, 1, 73-76.

Kılıç E, Özaydın I, Aksoy O, Yayla S, Sözmen M, 2006: Multiple urogenital system anomalies in three calves. Kafkas Üniv Vet Fak Derg, 12, 2, 193-197.

Kılıç E, Baran V, Yayla S, Özen H, 2015: Bir tuj ırkı kuzuda atresia ani, atresia vulva ve rektovaginal fistül anomalisi. Erciyes Üniv Vet Fak Derg, 12, 3, 219-222.

Krishna H, Prasad VD, Rao M, 2009: Agenesis of vulva and terminal urethra with atresia ani et recti in a buffalo calf. Buffalo Bulletin, 28, 4, 165-167.

Shakoor A, Muhammad SA, Younus M, Kashif M, 2012: Surgical repair of congenital recto-vaginal fistula with atresia ani in a cow calf. Pak Vet J, 32 (2), 298300.
Şındak N, Şahin T, Biricik HS, 2010: Urethral dilatation, ectopic testis, hypoplasia penis, and phimosis in a kilis goat kid. Kafkas Üniv Vet Fak Derg, 16, 1, 147150.

Yayla S, Kılıç E, Baran V, Özen H, 2016: A case of congenital rectourethral fistula, urethral dilatation and segmental urethral agenesis encountered in a calf. Harran Üniv Vet Fak Derg, 5, 1, 70-73.

**: Bu olgu sunumu "XV. Ulusal Veteriner Cerrahi Kongresi I. Uluslararası Türkiye Veteriner Cerrahi Kongresinde" poster olarak sunulmuştur.

*Yazışma Adresi: Sadık YAYLA

Kafkas Üniversitesi, Veteriner Fakültesi, Cerrahi Anabilim Dalı, Kars, Türkiye. e-mail: sadikyayla@gmail.com 